\title{
DFT Study of Polythiophene Energy Band Gap and Substitution Effects
}

\section{Si. Mohamed Bouzzine, ${ }^{1,2}$ Guillermo Salgado-Morán, ${ }^{3}$ Mohamed Hamidi, ${ }^{2}$ Mohammed Bouachrine, ${ }^{4}$ Alison Geraldo Pacheco, ${ }^{5}$ and Daniel Glossman-Mitnik ${ }^{6}$}

\author{
${ }^{1}$ Regional Center for Trades and Professional Education, annex Errachidia, BP 8, 52000 Meknes, Morocco \\ ${ }^{2}$ Equipe d'Electrochimie et Environnement, Faculté des Sciences et Techniques, Université Moulay Ismail, \\ B.P. 509 Boutalamine, 52000 Errachidia, Morocco \\ ${ }^{3}$ Departamento de Ciencias Químicas, Facultad de Ciencias Exactas, Universidad Andrés Bello, \\ Sede Concepción, 4070000 Concepción, Chile \\ ${ }^{4}$ High School of Technology, University Moulay Ismail, Route d'Agouray, Km 5, BP 3102, Toulal, 50000 Meknes, Morocco \\ ${ }^{5}$ Instituto Federal de Educação Ciência e Tecnologia do Sul de Minas Gerais, 37576-000 Inconfidentes, MG, Brazil \\ ${ }^{6}$ Laboratorio Virtual NANOCOSMOS, Departamento de Medio Ambiente y Energía, Centro de Investigación \\ en Materiales Avanzados, 31136 Chihuahua, CHIH, Mexico
}

Correspondence should be addressed to Daniel Glossman-Mitnik; daniel.glossman@cimav.edu.mx

Received 2 March 2015; Revised 23 April 2015; Accepted 29 April 2015

Academic Editor: Rocío Sánchez-de-Armas

Copyright (C) 2015 Si. Mohamed Bouzzine et al. This is an open access article distributed under the Creative Commons Attribution License, which permits unrestricted use, distribution, and reproduction in any medium, provided the original work is properly cited.

\begin{abstract}
Polythiophene (PTh) and its derivatives are polymer-based materials with a $\pi$-conjugation framework. PTh is a useful photoelectric material and can be used in organic semiconductor devices, such as PLED, OLED, and solar cells. Their properties are based on molecular structure; the derivatives contain different substitutes in the 3 and 5 positions, such as electron-donating or electronwithdrawing groups. All molecular geometries were optimized at B3LYP/6-31G(d,p) level of theory. The energy gap $\left(E_{\text {gap }}\right)$ between the HOMO and LUMO levels is related to the $\pi$-conjugation in the PTh polymer backbone. In this study, the DFT calculations were performed for the nonsubstituted and 3,5-substituted variants to investigate the stability geometries and electrical properties. The theoretical calculations show that the substituted forms are stable, have low $E_{\text {gap }}$, and are in good agreement with the experimental observations.
\end{abstract}

\section{Introduction}

Conjugated polymers are of considerable interest due to their electronic properties and their potential technological applications [1]. They have many advantages compared to inorganic semiconductors, such as easy processing and tunable optical gaps. Their electronic properties are determined by the delocalized $\pi$-electrons along their carbon backbone [2]. Polythiophene is the most important conjugated polymer utilized in a broad spectrum of applications such as conducting polymers, light-emitting diodes, field effect transistors, and plastic solar cells, due to its excellent optical and electrical properties as well as exceptional thermal and chemical stability. Early syntheses of poly(3-alkythiophene) involved chemical oxidation or electrochemical polymerization in the pursuit of soluble and processable polythiophenes [3-5]. However, these processes suffered from the major problem that the structure of the polymer is somewhat uncertain and undefined $[6,7]$. As 3-alkylthiophene is an asymmetric molecule, there are three possible orientations available when the two thiophene rings are coupled between the 2 and 5 positions. The first of these is the $2-5^{\prime}$ or head-to-tail coupling (HT). The second is $2-2^{\prime}$ or head-to-head coupling $(\mathrm{HH})$, and the third is $5-5^{\prime}$ or tail-to-tail coupling (TT) (see Figure 1).

Polythiophene (PTh) and its derivatives are used in several applications such as displays, electromagnetic shielding, and molecular electronics [8] and, due to them being thermally stable at ambient temperatures, have been used in new 


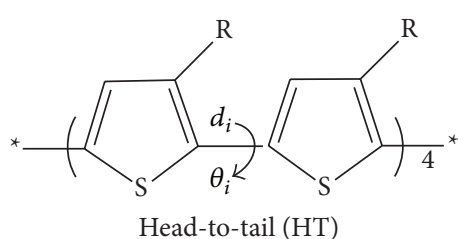

$\mathrm{R}=\mathrm{OC} \longrightarrow 8 \mathrm{TOC}(\mathrm{HT})$

$\mathrm{R}=\mathrm{COC} \longrightarrow 8 \mathrm{TCOC}(\mathrm{HT})$

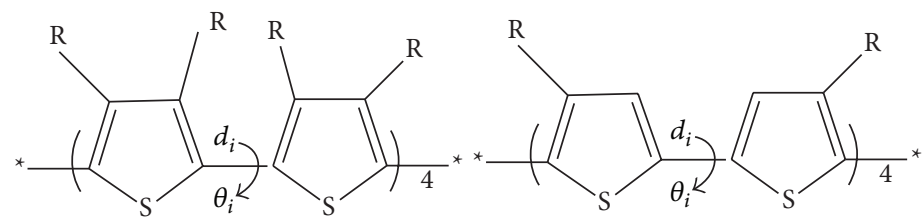

Tail-to-tail (TT)

$$
\begin{gathered}
\mathrm{R}=\mathrm{H} \longrightarrow 8 \mathrm{~T} \\
\mathrm{R}=\mathrm{OOC} \longrightarrow 8 \mathrm{TOOC}
\end{gathered}
$$

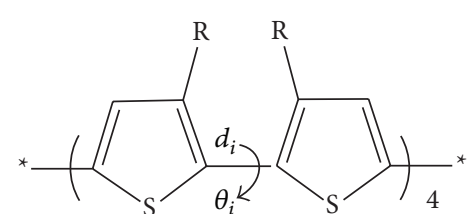

Head-to-head $(\mathrm{HH})$

$\mathrm{R}=\mathrm{COC} \longrightarrow 8 \mathrm{TCOC}(\mathrm{HH})$

$\mathrm{R}=\mathrm{OC} \longrightarrow 8 \mathrm{TOC}(\mathrm{HH})$

FIGURE 1: Sketch map of the structures, length bond, and dihedral angle.

optical devices such as surface light-emitting diodes (SLED) and light-emitting diodes (LED) [9]. One of the main goals in the field of electrically conducting polymers is to develop a complete understanding of the relationship between the chemical structure of the polymer and its electronic and conduction properties. Once such an insight is achieved, the desired electronic properties could be obtained by specific synthesis following molecular design. The conduction properties of an undoped polymer, in terms of the band theory of solids, are known to be related to its electronic properties, such as the ionization potential (IP), electronic affinity (EA), and band gap $\left(E_{\text {gap }}\right)$ [10]. The key factor that determines the intrinsic properties of the polythiophene variants is their band structures, particularly the positions of the conduction and valence bands and the gap between them. Therefore, the $\pi$-electrons in conducting polymers play a major role in determining their electrical conductivity and band structure [11]. The energy between the valence and conduction band of a polymer is related to the lowest energy of its monomer units and to the bandwidth resulting from the overlap between the monomer orbitals [12]. A band gap is defined as the difference between the highest occupied molecular orbital (HOMO) and the lowest unoccupied molecular orbital (LUMO) energy levels in the polymer [13]:

$$
E_{\text {gap }}=E_{\mathrm{LUMO}}-E_{\mathrm{HOMO}}(\mathrm{ev}) .
$$

So the electrical conductivity is directly related to the HOMO and LUMO energy of the molecule.

\section{Methods: Computational Details}

Full geometry optimizations were performed, under no constraints, in the framework of the density functional theory (DFT) by means of the B3LYP functional [the Becke3 and the Lee-Yang-Parr hybrid functional], using the Gaussian 09 program [14]. The 6-31G(d,p) basis set was chosen as a compromise between the quality of the theoretical approach and the high computational cost associated with the high number of dimensions to the problem $[15,16]$.

The HOMO, LUMO, and energy gaps were also deduced from the stable structure of the nonsubstituted forms. In this paper, the transition energies were calculated at the ground state geometries using TD-DFT/B3LYP calculations, and the results were compared with the available experimental data. A newly designed function, the long-range Coulomb-attenuating method (CAM-B3LYP), considered long-range interactions by comprising $19 \%$ of $\mathrm{HF}$ and $81 \%$ of $\mathrm{B} 88$ exchange at short range and $65 \%$ of $\mathrm{HF}$ plus $35 \%$ of $\mathrm{B} 88$ at long range [17]. Furthermore, the CAM-B3LYP method has been applied and was found to be reasonably capable of predicting the excitation energies and the absorption spectra of the molecules [18-21]. Therefore, the vertical excitation energy and electronic absorption spectra were simulated using the TD-CAM-B3LYP method in this work. The investigated polymers, $8 \mathrm{~T}, 8 \mathrm{TCOO}$, and $8 \mathrm{TOC}(\mathrm{HH}, \mathrm{HT}$, and TT) and 8TCOC (HH, HT, and TT), are depicted in Figure 1.

\section{Results and Discussion}

3.1. Geometric Properties. For all molecules, geometrical parameters were obtained after total optimization by B3LYP/ $6-31 G(d, p)$. To investigate the effect of the substituents on the geometries and electronic properties, the optimized structures of several substituted oligomers built on thiophene 8TOOC, 8TCOC (HH, HT, and TT), and 8TOC $(\mathrm{HH}, \mathrm{HT}$, and TT) are compared with the unsubstituted one, $8 \mathrm{~T}$. On the other hand, to investigate the effects of different regioregularities, ( $\mathrm{HH}, \mathrm{HT}$ and TT) are compared between them and with 
TABLE 1: Values of interring bond lengths $d_{i}(\AA)$ of the studied compounds obtained by B3LYP/6-31G(d,p) level.

\begin{tabular}{|c|c|c|c|c|c|c|c|c|}
\hline \multicolumn{2}{|c|}{ Compounds } & $d_{1}$ & $d_{2}$ & $d_{3}$ & $d_{4}$ & $d_{5}$ & $d_{6}$ & $d_{7}$ \\
\hline \multicolumn{2}{|l|}{$8 \mathrm{~T}$} & 1.445 & 1.441 & 1.440 & 1.440 & 1.440 & 1.441 & 1.445 \\
\hline \multirow{3}{*}{$8 \mathrm{TOC}$} & HT & 1.441 & 1.435 & 1.434 & 1.433 & 1.434 & 1.435 & 1.439 \\
\hline & $\mathrm{HH}$ & 1.445 & 1.434 & 1.438 & 1.432 & 1.438 & 1.434 & 1.445 \\
\hline & $\mathrm{TT}$ & 1.439 & 1.438 & 1.432 & 1.437 & 1.432 & 1.438 & 1.439 \\
\hline \multirow{3}{*}{ 8TCOC } & $\mathrm{HT}$ & 1.451 & 1.447 & 1.446 & 1.446 & 1.446 & 1.447 & 1.451 \\
\hline & $\mathrm{HH}$ & 1.449 & 1.456 & 1.446 & 1.454 & 1.446 & 1.454 & 1.448 \\
\hline & $\mathrm{TT}$ & 1.459 & 1.446 & 1.455 & 1.446 & 1.455 & 1.446 & 1.459 \\
\hline \multicolumn{2}{|c|}{$8 \mathrm{TOOC}$} & 1.442 & 1.439 & 1.438 & 1.438 & 1.438 & 1.439 & 1.442 \\
\hline
\end{tabular}

TABLE 2: Values of dihedral angle $\theta_{i}\left({ }^{\circ}\right)$ of the studied compounds obtained by B3LYP/6-31G(d,p) level.

\begin{tabular}{ccccccccc}
\hline Compounds & $\theta_{1}$ & $\theta_{2}$ & $\theta_{3}$ & $\theta_{4}$ & $\theta_{5}$ & $\theta_{6}$ & $\theta_{7}$ \\
\hline \multicolumn{1}{c}{ 8T } & 179.96 & 179.96 & 179.96 & 179.96 & 179.96 & 179.96 & 179.96 \\
\hline 8TOC & HT & 180 & 180 & 180 & 180 & 180 & 180 & 180 \\
& HH & 161.49 & 179.96 & 170.17 & 179.69 & 169.86 & 179.98 & 161.51 \\
TT & 180 & 180 & 180 & 180 & 180 & 180 & 180 \\
\hline HT & 146.37 & 155.18 & $156 / 94$ & 154.19 & 157.29 & 152.34 & 148.24 \\
8TCOC HH & 165.04 & 126.17 & 176.70 & 132.04 & 171.43 & $130 / 92$ & 162.30 \\
TT & 122.47 & 170.57 & 127.90 & 168.60 & 127.90 & 170.60 & 122.47 \\
\hline 8TOOC & 175.85 & 177.14 & 175.93 & 178.73 & 179.92 & 179.62 & 179.97
\end{tabular}

the $8 \mathrm{~T}$ and $8 \mathrm{TOOC}$ compounds. The geometric characteristics, given as interring distances $\left(d_{i}\right)$ and dihedral angle $\left(\theta_{i}\right)$, are listed in Tables 1 and 2.

The optimized structures (see Figure 4) of compounds (8TCOOC and 8TOC, with different regioregularities) are compared with each other and also with 8T and 8TOOC. The geometric characteristics are given as interring distances $\left(d_{i}\right)$ and used to investigate the effect of different regioregularities (HT, HH, and TT). The theoretical calculations show that the torsional angles are evaluated to be about $\approx 180^{\circ}$ (a quasiplanar conformation) for 8T and 8TOC (HT and TT conformations), whereas the other compounds show an antigauche angle with an average twist angle between $122^{\circ}$ and $170^{\circ}$ for $8 \mathrm{TCOC}(\mathrm{HH}$ and TT) and the $8 \mathrm{TCOC}(\mathrm{HT})$ shows the value of torsion angle between the values of $8 \mathrm{TCOC}(\mathrm{HH}$ and TT) of about $150^{\circ}$ (see Tables 1 and 2 and Figures 2 and 3 ).

The properties of the oligomer for 8TOC (HT and TT) can be explained by the effects of the $\mathrm{OCH}_{3}$ donor group compared with the $\mathrm{CH}_{2}-\mathrm{OCH}_{3}$ group. The electronic doublet of the methoxy group increases the conjugation, which promotes better flatness of the system, in contrast to the $\mathrm{CH}_{2} \mathrm{OCH}_{3}$ group. These results are audited by the intercyclic study of the values of the bindings. This shows that, in going from the $8 \mathrm{~T}$ compound to $8 \mathrm{TOOC}$ and $8 \mathrm{TOC}(\mathrm{HH}, \mathrm{TT}$, and HT) compounds, there is a reduction of the values of the interring bindings (see Tables 1 and 2 and Figures 2 and 3 ). These results may be explained by a repulsion of the $\mathrm{OOCH}_{3}$ (8TOOC) and $\mathrm{OCH}_{3}$ (8TOC) groups among them that favors the flatness of these systems. The comparison of the values of the bindings of intercyclic $8 \mathrm{~T}$ compounds with $8 \mathrm{TCOC}$ shows an increase of these values for those systems with antigauche torsion angles and indicates the strong interaction (attraction) of the $\mathrm{CH}_{2} \mathrm{OCH}_{3}$ groups among them.

3.2. Electronic Parameters. Table 3 lists the theoretical electronic parameters of the studied conjugated compounds. The calculated electronic parameters ( $E_{\text {gap }}$, LUMO, and HOMO) of compounds $8 \mathrm{~T}, 8 \mathrm{TCOC}(\mathrm{HH}, \mathrm{HT}$, and TT), 8TOOC, and 8TOC (HH, HT, and TT) exhibit the destabilization of the HOMO and LUMO levels in comparison with those of the unsubstituted one (8T) due to electron-donating substitution groups, while, in the case of $8 \mathrm{TOC}$, there is a net stabilization of the HOMO and LUMO levels. However, these compounds have a smaller energy gap $\left(E_{\text {gap }}\right)$ than the unsubstituted one, which is due to the presence of a methoxy group in the $\beta$ position of the thiophene ring. The band gap of 8TOC is much smaller than that of the other substituted compounds. This may be attributed to the number of electron-donating methoxy side groups and also to the Coulombic interaction between the sulfur of thiophene and oxygen atoms [27, 28]. The theoretical band gaps computed for isolated chains are expected to be about $0.2 \mathrm{eV}$ larger than the values computed in the condensed phase [29]. When taking into account this difference, the band gap values obtained are close to the experimental data for the octamer. The value of the octamer's $8 \mathrm{~T}$ and $8 \mathrm{TOC}$ band gap $(2.22 \mathrm{eV}$ and $1.93 \mathrm{eV}$, resp., after correction) is in accordance with that measured experimentally for polythiophene, $2.0-2.3 \mathrm{eV}[30,31]$, and that for poly $\left(4,4^{\prime}\right.$-dimethylbithiophene (8TOC (TT)) ) was estimated to be $1.6 \mathrm{eV}$ [23]. The octamer seems to be a useful model to obtain a better understanding of the electronic properties of the polymeric system.

It is important to examine the HOMO and the LUMO energies for these oligomers because the relative ordering of the occupied and virtual orbital provides a reasonable qualitative indication of excitation properties. In general, as shown in Figure 5 (LUMO, HOMO), the HOMOs of these oligomers possess a $\pi$-bonding character within a subunit and a $\pi$ antibonding character between the consecutive subunits. On the other hand, the LUMOs possess a $\pi$-antibonding character within a subunit and a $\pi$-bonding character between the subunits. The experiment shows that the HOMO and LUMO energies are obtained from an empirical formula based on the onset of the oxidation and reduction peaks measured by the cyclic voltammetry. In theory, the HOMO and LUMO energies can be calculated by the DFT calculation $[32,33]$. However, it is noticeable that solid-state packing effects are not included in the DFT calculations, which tend to affect the HOMO and LUMO energy levels in a thin film compared with an isolated molecule, as considered in the calculations. Even if these calculated energy levels are not accurate, it is possible to use them to obtain the information by comparing similar oligomers or polymers. The calculated electronic parameters (Gap, HOMO, and LUMO) of compounds $8 \mathrm{~T}$, 8TOOC, $8 \mathrm{TOC}(\mathrm{HH}, \mathrm{HT}$, and HT), and $8 \mathrm{TCOC}(\mathrm{HH}, \mathrm{HT}$, and HT) are illustrated in Table 3.

In the case of compounds 8TOC, 8TOOC, and 8TCOC, it is notable that there is a systematic change of the HOMO and LUMO energies into the backbone; substitution raises 

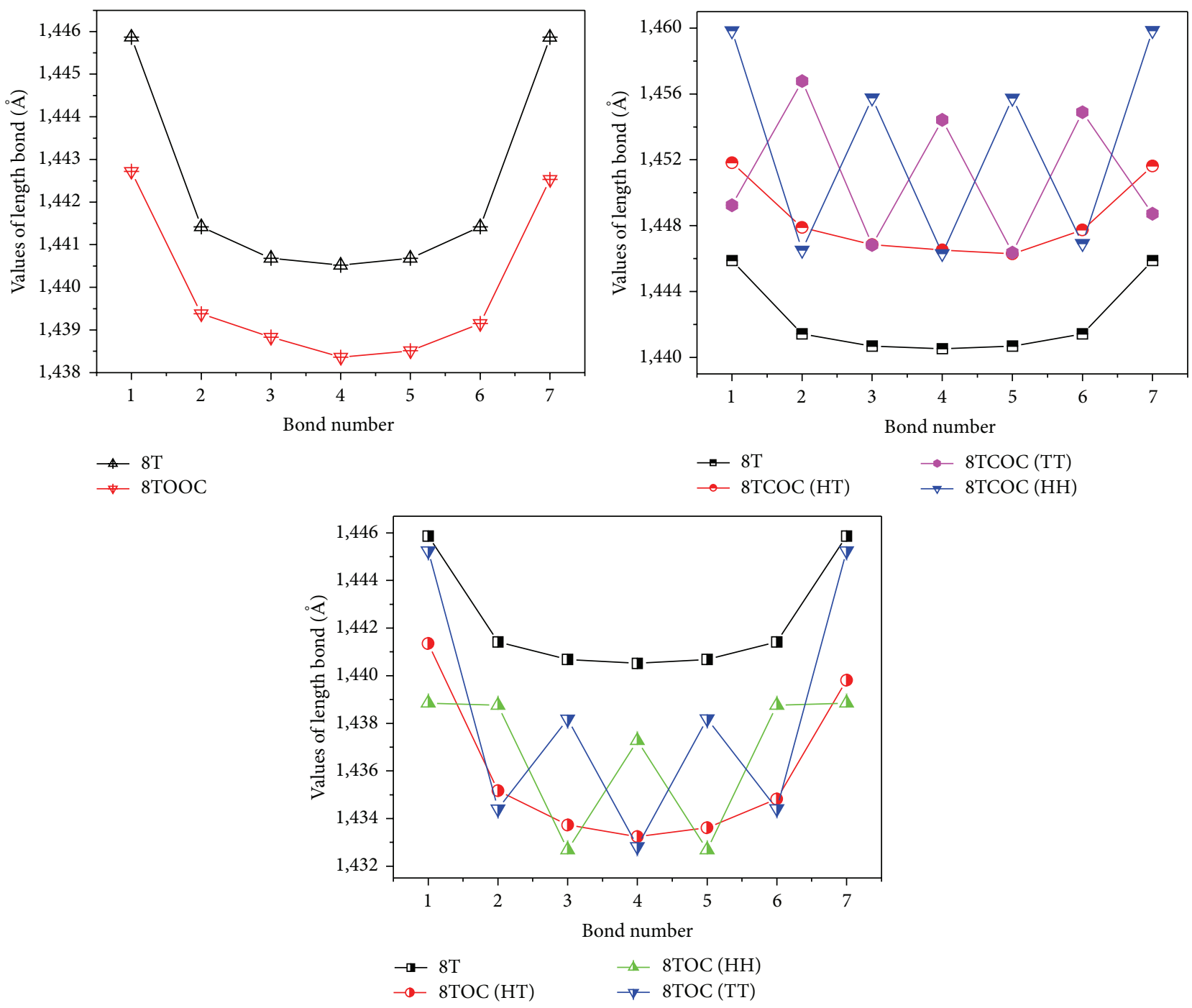

Figure 2: Optimized C-C bond lengths interring of 8T, 8TOOC, 8TCOC (HH, HT, and TT), and 8TOC (HH, HT, and TT) in neutral states with the number of bonds, studied by B3LY/6-31G(d,p) level.

TABLE 3: Energy values of $E_{\mathrm{LUMO}}(\mathrm{eV}), E_{\mathrm{HOMO}}(\mathrm{eV}), E_{\text {gap }}(\mathrm{eV})$, and the open circuit voltage $V_{\mathrm{oc}}(\mathrm{eV})$ of the studied molecules.

\begin{tabular}{|c|c|c|c|c|c|c|}
\hline \multicolumn{2}{|c|}{ Compounds } & $E_{\text {HOMO }}(\mathrm{eV})$ & $E_{\text {LUMO }}(\mathrm{eV})$ & $E_{\text {gap }}(\mathrm{eV})$ & $E_{\text {gap }}(\mathrm{eV}) \exp$ & $V_{\text {oc }}(\mathrm{eV})$ \\
\hline \multicolumn{2}{|c|}{$8 \mathrm{~T}$} & -4.73 & -2.31 & 2.42 & $2.00[22]$ & 0.73 \\
\hline \multicolumn{2}{|c|}{ 8TOOC } & -4.16 & -1.70 & 2.46 & & 0.16 \\
\hline \multirow{3}{*}{ 8TCOC } & $(\mathrm{HT})$ & -4.62 & -1.96 & 2.66 & & 0.62 \\
\hline & $(\mathrm{HH})$ & -4.90 & -1.88 & 3.02 & & 0.90 \\
\hline & $(\mathrm{TT})$ & -4.91 & -1.81 & 3.10 & & 0.91 \\
\hline \multirow{3}{*}{ 8TOC } & $(\mathrm{HT})$ & -3.87 & -1.96 & 1.91 & & - \\
\hline & $(\mathrm{HH})$ & -3.89 & -1.82 & 2.07 & & - \\
\hline & $(\mathrm{TT})$ & -3.99 & -1.86 & 2.13 & $1.6[23]$ & - \\
\hline \multicolumn{2}{|c|}{ PCBM $[24,25]$} & -6.10 & -3.70 & & & \\
\hline
\end{tabular}

or lowers the HOMO/LUMO energies in agreement with their electron donor character. However, these compounds have a smaller energy gap $\left(E_{\text {gap }}\right)$ than the unsubstituted one (8T), which is due to the presence of different substituents as described previously $[34,35]$. The band gap of 8 TOC ( $\mathrm{HH}, \mathrm{TT}$, and HT) is much smaller than that of the other substituted compounds. This may be attributed to the number of electron-donating methoxy side groups. 

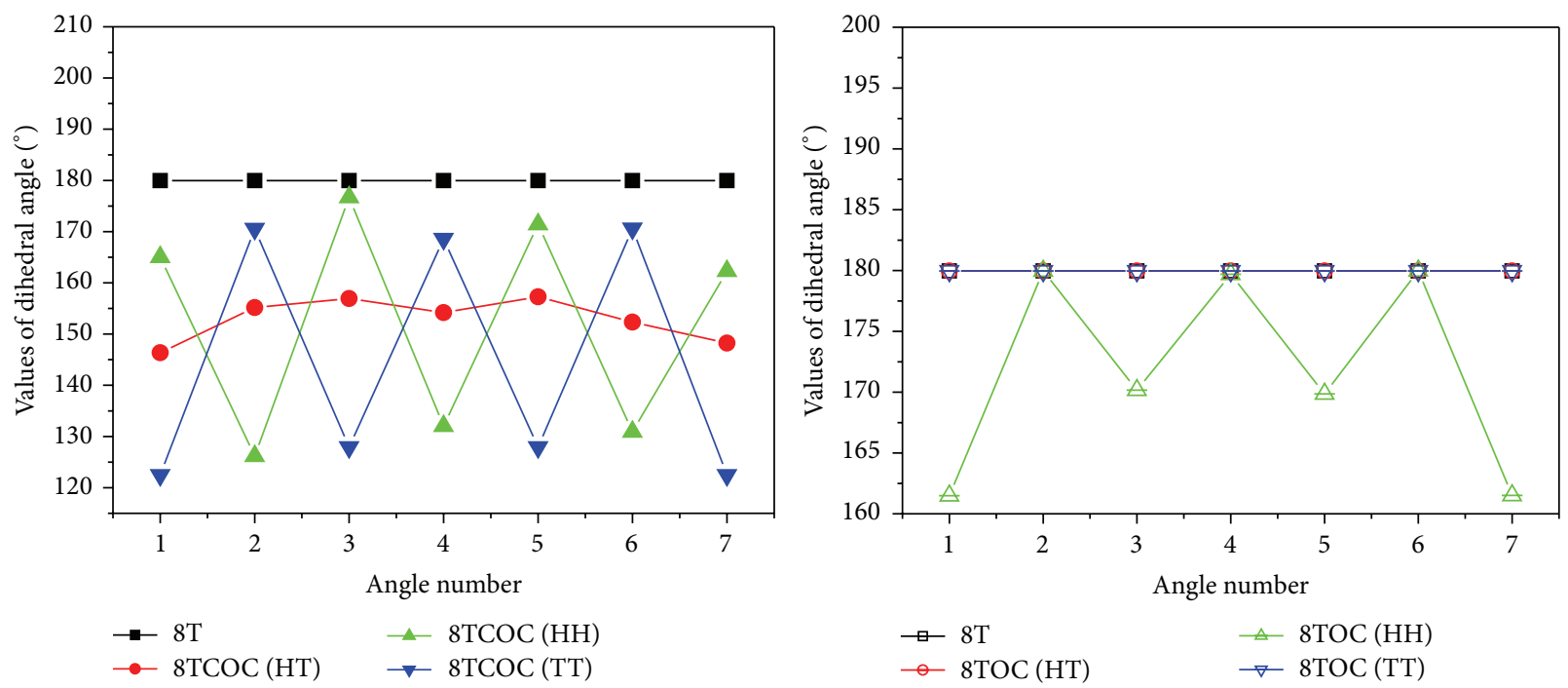

Figure 3: Optimized dihedral angle of 8T, 8TCOC (HH, HT, and TT), and 8TOC (HH, HT, and TT) in neutral states with the number of bonds, studied by B3LY/6-31G(d,p) level.
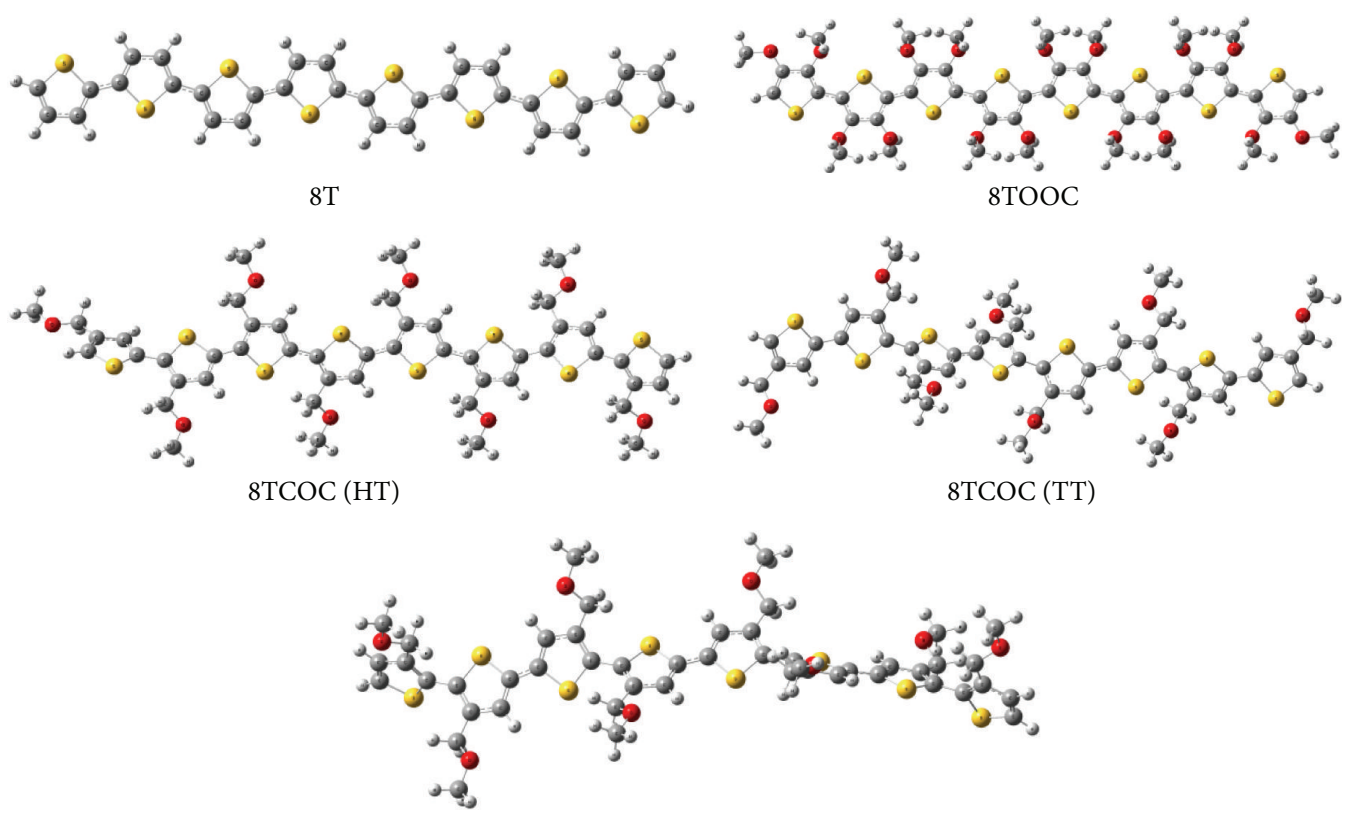

$8 \mathrm{TCOC}(\mathrm{HH})$
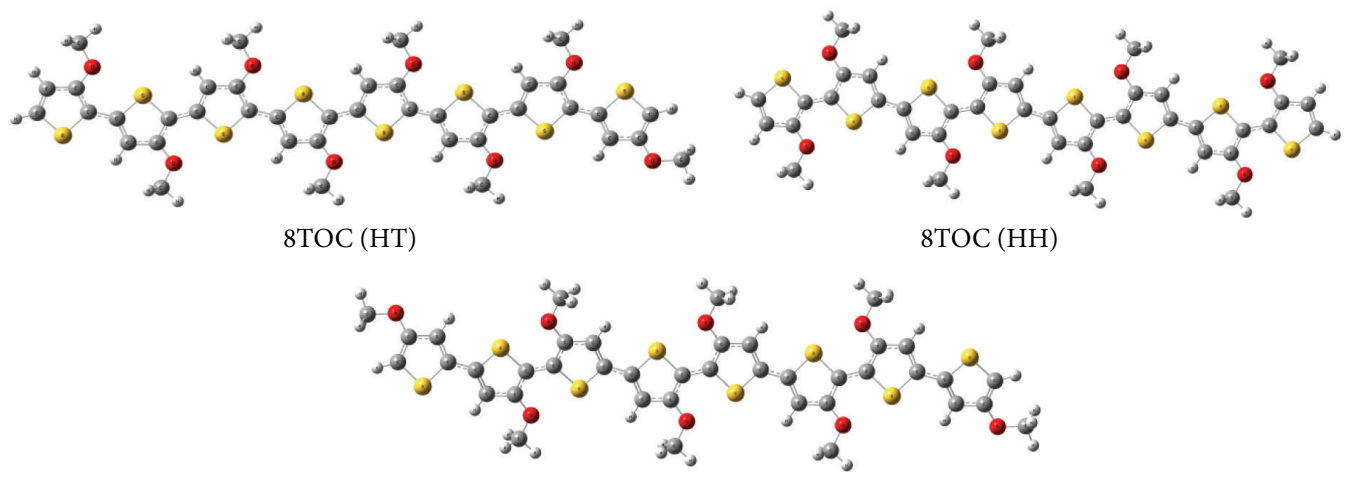

$8 \mathrm{TOC}(\mathrm{TT})$

FIGURE 4: Optimized structures of the studied oligomers. 
HOMO

2

: 20 900000030.8 o. $\int_{0}^{\infty} \int_{0}^{\infty}$

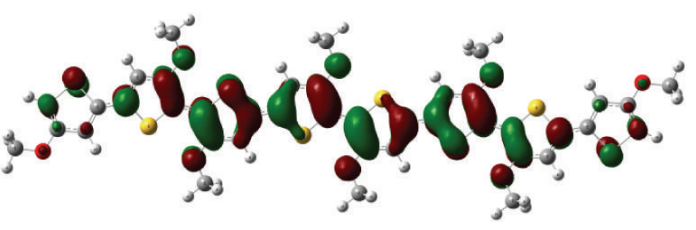
8TOC (HT)

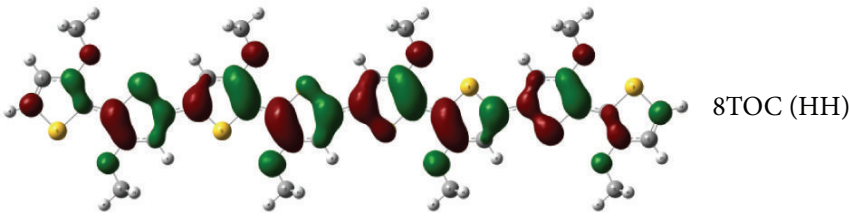

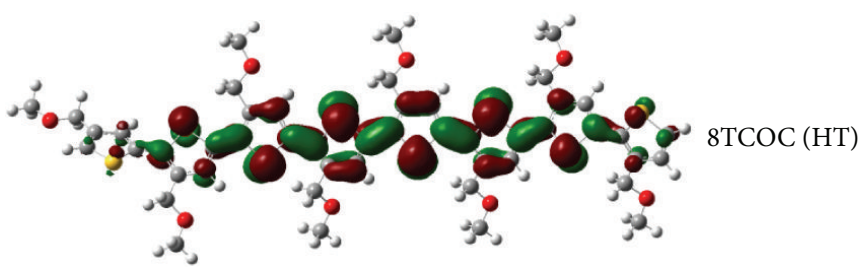

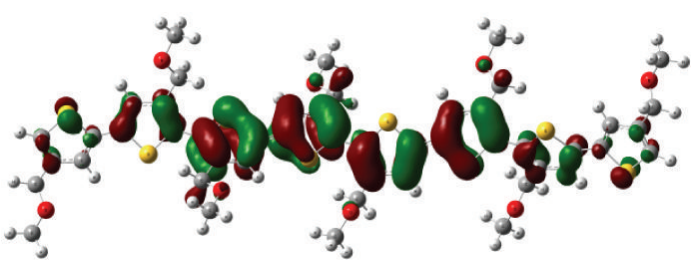

$8 \mathrm{TOC}$ (TT)

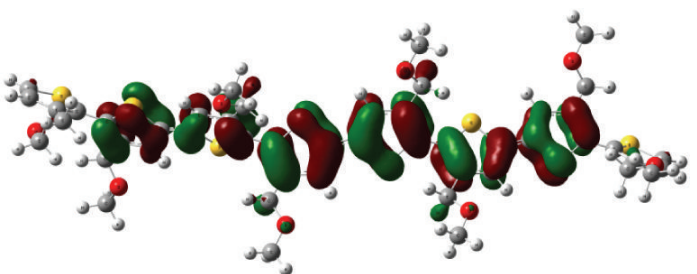

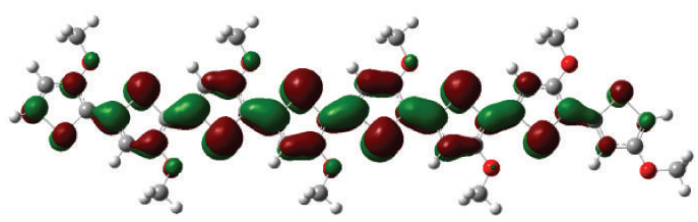
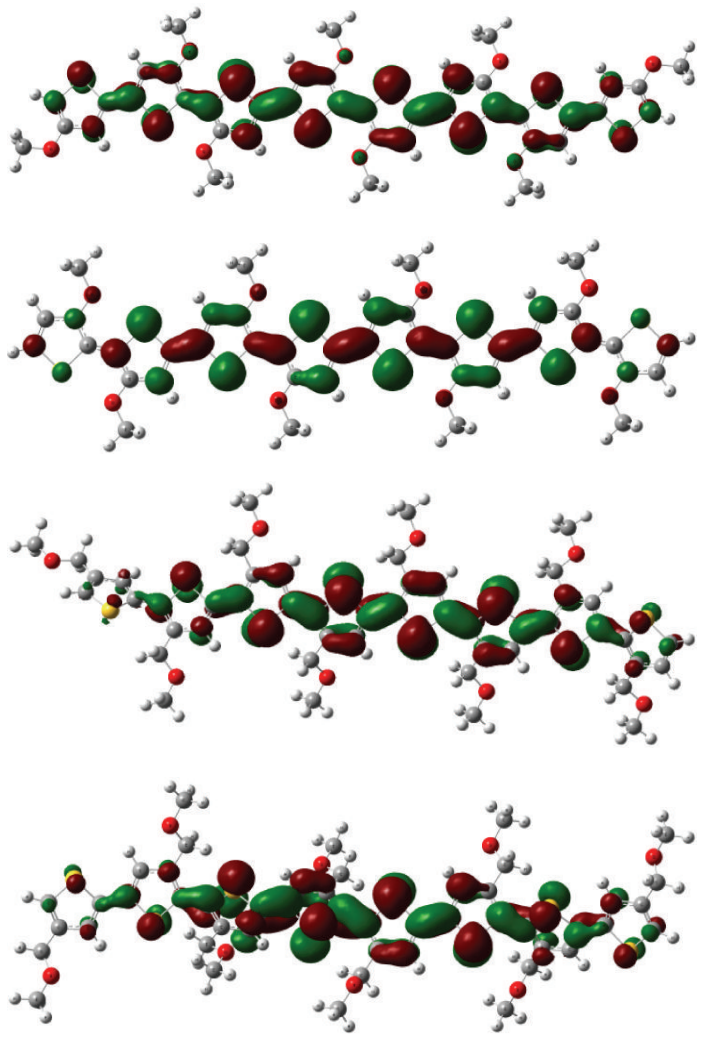

LUMO
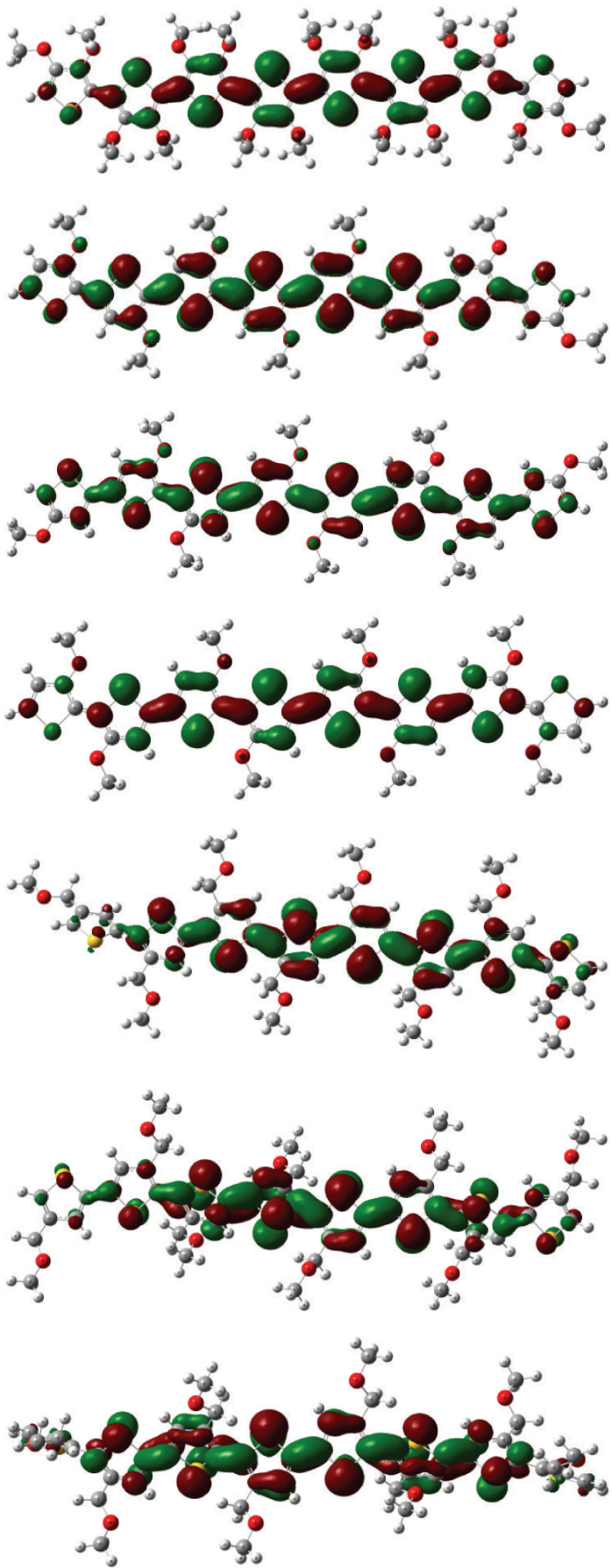

FIGURE 5: The contour plots of HOMO and LUMO orbitals of the studied compounds.

3.3. Photovoltaic Properties. Generally, the most efficient polymer solar cells are based on the bulk heterojunction (BHJ) structure of the blend of $\pi$-conjugated polymer donors and fullerene derivative acceptors [7, 36-40]. Here, we studied the photovoltaic properties of polyalkyl thiophene with
[6,6]-phenyl-C61-butyric acid methyl ester (PCBM), which is the most widely used acceptor in solar cell devices. The corresponding structure of the photovoltaic devices is schematically depicted in Figure 6 . The difference in the HOMO energy levels of $8 \mathrm{~T}, 8 \mathrm{TCOC}, 8 \mathrm{TOOC}$, and the LUMO of 


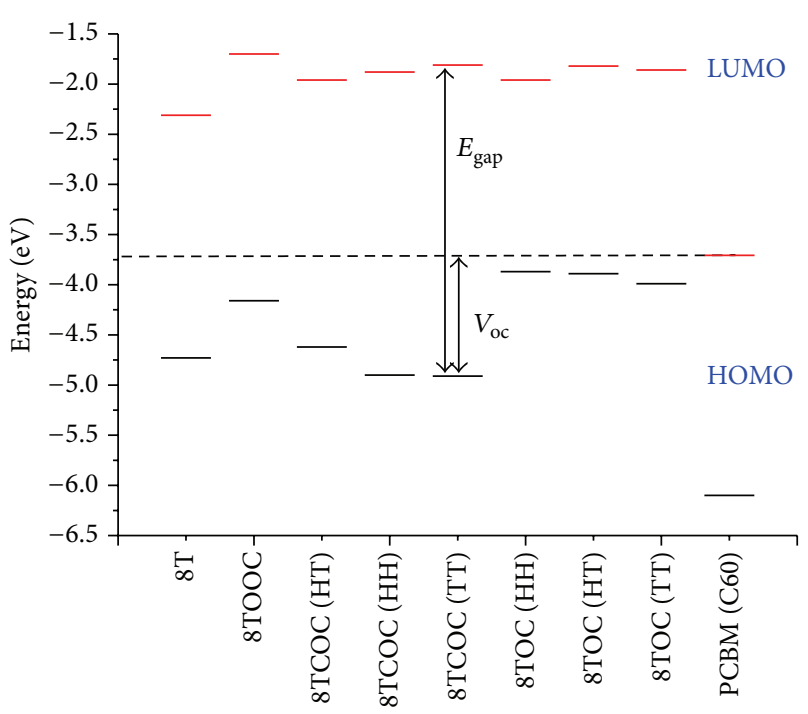

FIGURE 6: Band structure diagram illustrating the HOMO and LUMO energies of the studied compounds relative to the band structure of PCBM.

PCBM was $0.73 \mathrm{eV}, 0.16 \mathrm{eV}$, and $0.62 \mathrm{eV}$, respectively, but the value of $8 \mathrm{TOC}$ is negative (Table 3 ), suggesting that the photoexcited electron transfer from the study compounds to PCBM may be sufficiently efficient to be useful in photovoltaic devices [24, 41, 42].

In principle, the optimization of polymer-fullerene solar cells is based on fine-tuning the electronic properties and interactions of the donor and acceptor components so as to absorb the maximum quantity of light and generate the greatest number of free charges, with minimal concomitant loss of energy and transport the charges to the electrodes. However, it is necessary to know the ideal electronic characteristics that each component should have for the design of the next generation, high-efficiency photovoltaic systems. The two components required in these devices for electronic optimization are a soluble fullerene (generally a C60 derivative) acceptor and a polymeric donor that can be processed in solution. Fullerenes are currently considered to be the ideal acceptors for organic solar cells for several reasons. First, they have an energetically deep-lying LUMO which endows the molecule with a very high electron affinity relative to the numerous potential organic donors [25].

It is apparent that the active layer donor-acceptor composite governs all aspects of the mechanism, with the exception of charge collection, which is based on the electronic interface between the active layer composite and the respective electrode. Besides the fundamental mechanistic steps, the open circuit voltage $\left(V_{\text {oc }}\right)$ is also governed by the energetic relationship between the donor and the acceptor (Figure 6) rather than the work functions of the cathode and anode, as would be expected from a simplistic view of these diode devices. Specifically, the energy difference between the HOMO of the donor and the LUMO of the acceptor is found to be very closely correlated with the $V_{\text {oc }}$ value [43-45].
The maximum open circuit voltage $\left(V_{\mathrm{oc}}\right)$ of the $\mathrm{BHJ}$ solar cell is related to the difference between the highest occupied molecular orbital (HOMO) of the electron donor and the LUMO of the electron acceptor, taking into account the energy lost during the photocharge generation [46]. The theoretical values of open circuit voltage $V_{\text {oc }}$ have been calculated from the following expression:

$$
V_{\mathrm{oc}}=\left|E_{\mathrm{HOMO}}{ }^{\text {(Donor) }}\right|-\left|E_{\mathrm{LUMO}}{ }^{\text {(Acceptor) }}\right|-0.3 .
$$

Moreover, these compounds have absorption maxima in the neighborhood of $400-540 \mathrm{~nm}$ (Table 4) which is the optimum range of absorption (UV-visible) for photovoltaic cells. In addition, they have an energy gap of the order of $2.00 \mathrm{eV}$ (Table 3) for the elevation of the electron from the HOMO to the LUMO orbitals. This characteristic allows us to promote these compounds for the production of solar cells. These values are sufficient for a possible efficient electron injection system. Therefore, all the studied molecules can be used as organic solar cell components because the electron injection process from the excited molecule to the conduction band of the acceptor (PCBM) and the subsequent regeneration is possible in photovoltaic cells.

\section{Optoelectronic Parameters}

4.1. Electronic Absorption Spectra. For a better understanding of the electronic properties of thiophene-based molecules, the excitation energy based on the first and second singletsinglet electronic transitions has been studied. In recent years, time dependent density functional theory (TD-DFT) has emerged as a reliable standard tool for the theoretical treatment of electronic excitation spectra and recent works demonstrate better accuracy for a wide range of systems [47, 48]. The TD-DFT/B3LYP/6-31G(d,p) has been used on the basis of the optimized geometry. The nature and the energy of the singlet-singlet electronic transitions of all the oligomers in all series under study are reported in Table 4 . All electronic transitions are $\pi \rightarrow \pi^{*}$ type and no localized electronic transitions are exhibited among the calculated singlet-singlet transition. Table 4 summarizes the transition energies of absorption spectra and oscillator strength. Two interesting trends in oscillator strength can be found in all series of compounds: the oscillator strength OS of $S_{0} \rightarrow S_{1}$ is the overwhelmingly largest of all the series of polymers.

According to Table 4, we note an excitation energy of about $2 \mathrm{eV}$ for all compounds studied. In addition, absorption maxima were located in the $400-540 \mathrm{~nm}$ range for all compounds, indicating all molecules have only one band in the visible region $\left(\lambda_{\mathrm{abs}}>400 \mathrm{~nm}\right)$. The absorption spectra of these compounds showed a major absorption band assigned to the $\pi \rightarrow \pi^{*}$ transition local electron.

According to the transition character, most of the compounds show the HOMO $\rightarrow$ LUMO transition as the first singlet excitation. The maximum $\left(\lambda_{\max }\right)$ wavelengths for UVvis absorption spectra of all compounds simulated are shown in Figure 7. The calculated $\lambda_{\max }$ by TD-DFT-B3LY and TDCAM-B3LYP is different by about $99 \mathrm{~nm}=\lambda_{\max }(\mathrm{B} 3 \mathrm{LYP})-$ $\lambda_{\max }($ CAM-B3LYP). 
TABLE 4: Excitation energy values $\Delta E$ for the studied compounds obtained by TD-DFT/CAM-B3LYP, TD-DFT/ B3LYP with 6-31G (d,p) level.

\begin{tabular}{|c|c|c|c|c|c|c|c|c|}
\hline \multirow{2}{*}{ Compounds } & \multirow{2}{*}{$\lambda(\mathrm{nm}) \operatorname{Exp}[26]$} & \multicolumn{2}{|c|}{ TD-B3LYP } & \multicolumn{2}{|c|}{ TD-CAM-B3LYP (DMSO) } & \multicolumn{3}{|c|}{ TD-CAM-B3LYP } \\
\hline & & $\lambda(\mathrm{nm})$ & $E(\mathrm{eV})(\mathrm{OS})$ & $\lambda(\mathrm{nm})$ & $E(\mathrm{eV})(\mathrm{OS})$ & $\lambda(\mathrm{nm})$ & $E(\mathrm{eV})(\mathrm{OS})$ & Molecular orbital \\
\hline \multirow{3}{*}{$8 \mathrm{~T}$} & \multirow{3}{*}{448} & 644.59 & $1.92(2.9063)$ & 493.62 & $2.51(3.0912)$ & 478.07 & $2.59(2.9578)$ & \multirow{3}{*}{$\mathrm{H} \rightarrow \mathrm{L}(0.63)$} \\
\hline & & 553.29 & $2.24(0.000)$ & 410.15 & $3.02(0.000)$ & 392.33 & $3.10(0.0000)$ & \\
\hline & & 536.39 & $2.31(0.000)$ & 323.15 & $3.83(0.000)$ & 323.00 & $3.83(0.0000)$ & \\
\hline \multicolumn{9}{|l|}{$8 \mathrm{TOC}$} \\
\hline \multirow{4}{*}{ HT } & \multirow{9}{*}{465} & 717.23 & $1.72(1.4020)$ & 545.14 & $2.27(3.2032)$ & 529.71 & $2.34(2.9449)$ & \multirow{4}{*}{$\mathrm{H} \rightarrow \mathrm{L}(0.64)$} \\
\hline & & 557.36 & $2.22(1.6056)$ & 437.88 & $2.83(0.0002)$ & 420.71 & $2.94(0.0021)$ & \\
\hline & & 514.85 & $2.40(0.0072)$ & 365.82 & $3.38(0.2814)$ & 364.69 & $3.39(0.2123)$ & \\
\hline & & 661.72 & $1.87(2.8471)$ & 568.23 & $2.18(3.1391)$ & 544.55 & $2.27(3.0037)$ & \\
\hline \multirow[t]{3}{*}{$\mathrm{HH}$} & & 551.55 & $2.24(0.000)$ & 453.48 & $2.73(0.000)$ & 430.04 & $2.88(0.000)$ & $\mathrm{H} \rightarrow \mathrm{L}(0.64)$ \\
\hline & & 452.97 & $2.73(0.000)$ & 362.33 & $3.42(0.000)$ & 360.74 & $3.43(0.000)$ & \multirow{4}{*}{$\mathrm{H} \rightarrow \mathrm{L}(0.64)$} \\
\hline & & 646.58 & $1.91(2.8253)$ & 555.33 & $2.23(3.0750)$ & 533.32 & $2.32(2.9676)$ & \\
\hline \multirow[t]{2}{*}{$\mathrm{TT}$} & & 537.95 & $2.30(0.000)$ & 442.30 & $2.80(0.0041)$ & 421.18 & $2.94(0.0035)$ & \\
\hline & & 475.32 & $2.60(0.000)$ & 355.93 & $\begin{array}{c}3.48 \\
(0.0004) \\
\end{array}$ & 354.62 & $3.49(0.0001)$ & \\
\hline \multicolumn{9}{|l|}{$8 \mathrm{TCOC}$} \\
\hline \multirow{3}{*}{ HT } & \multirow{9}{*}{ - } & 529.52 & $2.34(2.4562)$ & 450.23 & $2.75(2.5260)$ & 439.61 & $2.82(2.8030)$ & \multirow{3}{*}{$\mathrm{H} \rightarrow \mathrm{L}(0.62)$} \\
\hline & & 445.36 & $2.78(0.0966)$ & 381.34 & $3.25(0.0568)$ & 368.61 & $3.36(0.0488)$ & \\
\hline & & 422.03 & $2.93(0.0397)$ & 331.52 & $3.73(0.3015)$ & 322.30 & $3.84(0.2428)$ & \\
\hline \multirow{3}{*}{$\mathrm{HH}$} & & 472.08 & $2.62(2.1440)$ & 404.35 & $3.06(2.6989)$ & 396.18 & $3.12(2.5865)$ & \multirow{3}{*}{$\mathrm{H} \rightarrow \mathrm{L}(0.62)$} \\
\hline & & 408.34 & $3.03(0.0008)$ & 356.82 & $3.47(0.0998)$ & 346.23 & $3.58(0.0852)$ & \\
\hline & & 396.27 & $3.12(0.0661)$ & 319.08 & $3.88(0.2093)$ & 285.81 & $4.33(0.0000)$ & \\
\hline \multirow{3}{*}{$\mathrm{TT}$} & & 467.12 & $2.65(2.0300)$ & 411.63 & $3.01(2.7553)$ & 392.82 & $3.15(2.4701)$ & \multirow{3}{*}{$\mathrm{H} \rightarrow \mathrm{L}(0.62)$} \\
\hline & & 403.97 & $3.06(0.0042)$ & 361.59 & $3.42(0.0509)$ & 341.87 & $3.62(0.0641)$ & \\
\hline & & 398.18 & $3.11(0.0434)$ & 324.29 & $3.82(0.3900)$ & 313.40 & $3.95(0.4098)$ & \\
\hline \multirow{3}{*}{ 8TOOC } & & 573.29 & $2.16(2.6859)$ & 489,34 & $2.53(3.0704)$ & 474.22 & $2.61(2.9274)$ & \multirow{3}{*}{$\mathrm{H} \rightarrow \mathrm{L}(0.64)$} \\
\hline & - & 479.95 & $2.58(0.000)$ & 408.35 & $3.05(0.000)$ & 392.48 & $3.15(0.0001)$ & \\
\hline & & 445.88 & $2.78(0.000)$ & 348.35 & $3.55(0.2826)$ & 337.04 & $3.67(0.2340)$ & \\
\hline
\end{tabular}

The prediction of the excitation energies and oscillator strengths by using the CAM-B3LYP is in better agreement with the experimental results $[49,50]$ than is found for B3LYP, because the CAM- (Coulomb-attenuating method-) B3LYP also takes account of the long-range corrections for describing the long $\pi$-conjugation [51]. The results are shown in Table 4 , and we note that the excitation energy values $\Delta E$ obtained by TD-DFT/CAM-B3LYP/6-31G(d,p) level are in agreement with those obtained by the methods DFT/B3LYP/ 6-31G(d,p) level; therefore the CAM-B3LYP functional is very useful for predicting the excitation energies and oscillator strengths. The values calculated using the TD-DFT CAMB3LYP function of our compounds in vacuo for predicting the excitation energies and oscillator strengths are listed in Table 4. The TD/CAM-B3LYP/6-31G(d,p) method was also employed to simulate the optical property of the compounds.

4.2. Effect of Solvent. Solvent effects attract considerable attention because most of the chemical processes occur in the solution phase. The solvent effects are included here to ensure that the calculations are compatible with the typical conditions. The effects of chemical environment are discussed further as follows. In order to study the effect of solvents on the ground state molecular geometry, excitation energies and maximum absorption quantum chemical calculations on the studied molecules were carried out in vacuum, in dimethyl sulfoxide (DMSO). The longest wavelength peaks from CPCM-TD-CAM-B3LYP/6-31G(d,p) results are shifted compared to the corresponding ones using the TD-CAM-B3LYP results. The magnitudes of the spectral shifts are about $15 \mathrm{~nm}$ for 8T, 8TOC (HT), and 8TOOC and 18.81, 22.01, 23.68, 8.17, and $10.62 \mathrm{~nm}$ for $8 \mathrm{TCOC}(\mathrm{TT}), 8 \mathrm{TOC}(\mathrm{TT}), 8 \mathrm{TOC}(\mathrm{HH})$, 8TCOC $(\mathrm{HH})$, and 8TCOC $(\mathrm{HT})$, respectively. The absorption maxima of all compounds are further shifted by the effect of the dimethyl sulfoxide solvent. This might be related to the gradient electrostatic potential and donor effect of the $\mathrm{OCH}_{3}$, $\mathrm{CH}_{2} \mathrm{OCH}_{3}$, and $\mathrm{OOCH}_{3}$ groups. Further, there is a variation of the absorption maximum displacement for the same compound (HT, TT, and $\mathrm{HH}$ ); this is the result of the different configurations that one compound can take. In DMSO 

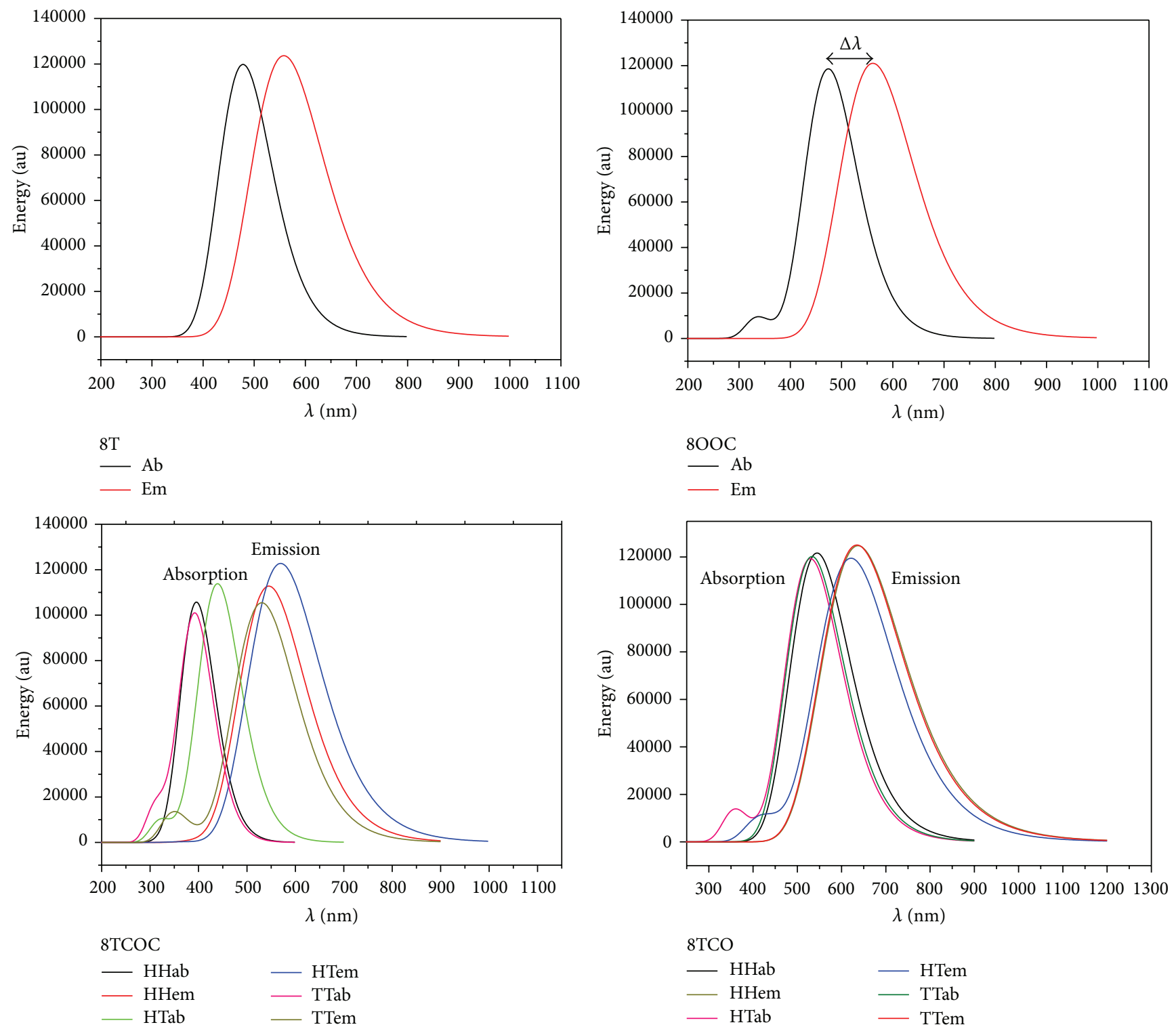

Figure 7: Calculated electronic absorption and emission of octamers units of 8T, 8TOC (HH, HT, and TT), 8TOOC, and 8TCOC (HH, HT, and TT) obtained by CAM-B3LYP/6-31G(d,p).

the calculated results for the absorption maximum of all compounds are located between 568.23 and $404.35 \mathrm{~nm}$ (Table 4). The peak positions of those molecules in DMSO show a red shift when compared to those measured experimentally [26].

\subsection{Electronic Emission Spectra. TD-DFT//B3LYP/6-31G(d,p)} has been used for optimized structures and CAM-B3LYP/6$31 \mathrm{G}(\mathrm{d}, \mathrm{p})$ was used to calculate the excited state and to simulate the emission spectra of the considered polymers and the first singlet excited states are listed in Table 5. Similar to the absorption spectra, $S_{1} \rightarrow S_{0}$ fluorescence peaks in emission spectra (Figure 6) have the greatest oscillator strengths in all molecules and exclusively arise from $\mathrm{HOMO} \rightarrow$ LUMO ( $\pi \rightarrow \pi^{*}$ electronic transition). Polymers with aromatic or heterocyclic units generally absorb light with wavelengths in the range from 300 to $700 \mathrm{~nm}$ due to $\pi \rightarrow \pi^{*}$ transitions. The excited states of their chromophores (excitons) release energy radiatively as well as nonradiatively on returning to the ground state [26]. The radiative decay of excitons to the ground state can emit visible light. These excitons are also formed when a bias potential is applied to an emissive polymer sandwiched between an anode and a cathode [52].

The theoretical studies of our molecules can be used to derive the Stokes shifts, the difference between the position of the maxima band of the absorption and emission spectra in wavelength, which is about 80 to $93 \mathrm{~nm}$ for the structures 8T, 8TOC (HH, TT, and HT), 8TCOC (TT), and 8TOOC, but that for the $8 \mathrm{TCOC}(\mathrm{HH})$ and $8 \mathrm{TCOC}(\mathrm{TT})$ is $149 \mathrm{~nm}$. Among them, the compound $8 \mathrm{TCOC}$ has a relatively larger Stokes shift, which indicates that electron transitions break 
TABLE 5: Emission spectra in gaseous phase obtained by the TDCAM-B3LYP/6-31G(d) optimized geometries of $S_{1}$ excited states for the octamers.

\begin{tabular}{|c|c|c|c|c|c|}
\hline \multicolumn{2}{|c|}{ Compounds } & $\lambda(\mathrm{nm})$ & $E(\mathrm{eV})$ & OS & $\Delta \lambda=\lambda \mathrm{ab}-\lambda \mathrm{em}$ \\
\hline \multirow{3}{*}{\multicolumn{2}{|c|}{$8 \mathrm{~T}$}} & 557.97 & 2.22 & 3.0531 & \multirow{3}{*}{79.8} \\
\hline & & 433.90 & 2.85 & 0.0000 & \\
\hline & & 365.64 & 3.39 & 0.0000 & \\
\hline \multirow{9}{*}{$8 \mathrm{TOC}$} & \multirow{3}{*}{ HT } & 621.47 & 1.99 & 2.9482 & \multirow{3}{*}{81.76} \\
\hline & & 461.13 & 2.68 & 0.0057 & \\
\hline & & 421.81 & 2.93 & 0.2710 & \\
\hline & \multirow{3}{*}{$\mathrm{HH}$} & 637.09 & 1.96 & 3.0801 & \multirow{3}{*}{92.54} \\
\hline & & 461.91 & 2.68 & 0.0000 & \\
\hline & & 406.54 & 3.04 & 0.0000 & \\
\hline & \multirow{3}{*}{$\mathrm{TT}$} & 621.47 & 1.99 & 2.9482 & \multirow{3}{*}{88.15} \\
\hline & & 461.13 & 2.68 & 0.0057 & \\
\hline & & 421.81 & 2.93 & 0.2710 & \\
\hline \multirow{9}{*}{$8 \mathrm{TCOC}$} & \multirow{3}{*}{$\mathrm{TT}$} & 530.79 & 2.33 & 2.6028 & \multirow{3}{*}{91.18} \\
\hline & & 400.43 & 3.09 & 0.0354 & \\
\hline & & 349.14 & 3.55 & 0.3253 & \\
\hline & \multirow{6}{*}{ HT } & 545.18 & 2.47 & 2.7840 & \multirow{3}{*}{149.00} \\
\hline & & 407.48 & 3.04 & 0.0275 & \\
\hline & & 355.60 & 3.48 & 0.0001 & \\
\hline & & 569.51 & 2.17 & 3.0310 & \multirow{3}{*}{176.69} \\
\hline & & 426.26 & 2.90 & 0.0001 & \\
\hline & & 367.84 & 3.37 & 0.0079 & \\
\hline \multirow{3}{*}{\multicolumn{2}{|c|}{$8 \mathrm{TOOC}$}} & 561.06 & 2.20 & 2.9875 & \multirow{3}{*}{86.84} \\
\hline & & 426.41 & 2.90 & 0.0002 & \\
\hline & & 364.21 & 3.40 & 0.0000 & \\
\hline
\end{tabular}

the strong conjugate effect, leading to remarkable changes in the structure and reorganization energy, as discussed above.

\section{Conclusions}

In this study, we have used the DFT/B3LYP method to investigate the theoretical analysis of the geometries and electronic properties of some type-in-derivatives structure of polythiophene. The modification of chemical structures can greatly modify and improve the electronic and optical properties of pristine studied materials. The electronic properties of the conjugated materials based on thiophene compounds have been computed using the 6-31G(d,p) basis set at a density functional B3LYP level, in order to guide the synthesis of novel materials with specific electronic properties.

In summary, the conclusions are as follows.

(i) The UV-vis absorption properties have been obtained by using TD/CAM-B3LYP and TD-B3LYP calculations. The obtained absorption maximums are in the range of $350-550 \mathrm{~nm}$.

(ii) The HOMO level, LUMO level, and band gap of the studied compounds were well controlled by the acceptor strength. The calculated band gap $\left(E_{\text {gap }}\right)$ of the studied molecules was in the range of 1.91-3.02 eV. (iii) The calculated values of $V_{\text {oc }}$ of the studied molecules range from $0.16 \mathrm{eV}$ to $0.91 \mathrm{eV} / \mathrm{PCBM}$; these values are sufficient for a possible efficient electron injection.

The theoretical results suggest that both the donor strength and the stable geometry contribute significantly to the electronic properties of the conjugated polymers. Finally, the procedures of theoretical calculations can be employed to predict the electronic properties of the other compounds and further to design novel materials for organic solar cells.

\section{Conflict of Interests}

The authors declare that there is no conflict of interests regarding the publication of this paper.

\section{Acknowledgments}

This work has been supported by the Volubilis Program (no. MA/11/248) and the convention CNRST/CNRS (Project Chimie 1009). The authors are grateful to the "Association Marocaine des Chimistes Théoriciens" (AMCT) for its pertinent help. Guillermo Salgado-Morán gratefully acknowledges Si. Mohamed Bouzzine for his invitation to participate in this work. Daniel Glossman-Mitnik is a researcher of CIMAV and CONACYT and acknowledges both institutions for partial support.

\section{References}

[1] H.-J. Wang, C.-P. Chen, and R.-J. Jeng, "Polythiophenes comprising conjugated pendants for polymer solar cells: a review," Materials, vol. 7, no. 4, pp. 2411-2439, 2014.

[2] S. Pesant, P. Boulanger, M. Côté, and M. Ernzerhof, "Ab initio study of ladder-type polymers: polythiophene and polypyrrole," Chemical Physics Letters, vol. 450, no. 4-6, pp. 329-334, 2008.

[3] J. Roncali, "Conjugated poly(thiophenes): synthesis, functionalization, and applications," Chemical Reviews, vol. 92, no. 4, pp. 711-738, 1992.

[4] Y. Wei, C.-C. Chan, J. Tian, G.-W. Jang, and K. F. Hsueh, "Electrochemical polymerization of thiophenes in the presence of bithiophene or terthiophene: kinetics and mechanism of the polymerization," Chemistry of Materials, vol. 3, no. 5, pp. 888897, 1991.

[5] R. M. Souto Maior, K. Hinkelmann, H. Eckert, and F. Wudl, "Synthesis and characterization of two regiochemically defined poly(dialkylbithiophenes): a comparative study," Macromolecules, vol. 23, no. 5, pp. 1268-1279, 1990.

[6] M.-A. Sato and H. Morii, "Nuclear magnetic resonance studies on electrochemically prepared poly(3-dodecylthiophene)," Macromolecules, vol. 24, no. 5, pp. 1196-1200, 1991.

[7] Y.-J. Cheng, S.-H. Yang, and C.-S. Hsu, "Synthesis of conjugated polymers for organic solar cell applications," Chemical Reviews, vol. 109, no. 11, pp. 5868-5923, 2009.

[8] A. C. Alguno, W. C. Chung, R. V. Bantaculo et al., "Ab initio and density functional studies of polythiophene energy band gap," NECTEC Technical Journal, vol. 2, no. 9, pp. 215-218, 2001.

[9] J. Pei, W.-L. Yu, W. Huang, and A. J. Heeger, "A novel series of efficient thiophene-based light-emitting conjugated polymers and application in polymer light-emitting diodes," Macromolecules, vol. 33, no. 7, pp. 2462-2471, 2000. 
[10] A. K. Bakhshi, "Theoretical tailoring of electrically conducting polymers: some new results," Materials Science and Engineering C, vol. 3, no. 3-4, pp. 249-255, 1995.

[11] M. S. Senevirathne, A. Nanayakkara, and G. K. R. Senadeera, "A theoretical investigation of band gaps of conducting polymerspolythiophene, polypyrrole and polyfuran," in Proceedings of the 23rd Technical Sessions, vol. 23, pp. 47-53, Institute of Physics, Colombo, Sri Lanka, March 2007.

[12] U. Salzner, J. B. Lagowski, P. G. Pickup, and R. A. Poirier, "Design of low band gap polymers employing density functional theory-hybrid functionals ameliorate band gap problem," Journal of Computational Chemistry, vol. 18, no. 15, pp. 1943-1953, 1997.

[13] E. Bundgaard and F. C. Krebs, "Low band gap polymers for organic photovoltaics," Solar Energy Materials and Solar Cells, vol. 91, no. 11, pp. 954-985, 2007.

[14] M. J. Frisch, G. W. Trucks, H. B. Schlegel et al., "Gaussian 09, Revision B.04," Gaussian, Inc., Wallingford, Conn, USA, 2009.

[15] M. E. Casida, C. Jamorski, K. C. Casida, and D. R. Salahub, "Molecular excitation energies to high-lying bound states from time-dependent density-functional response theory: characterization and correction of the time-dependent local density approximation ionization threshold," Journal of Chemical Physics, vol. 108, no. 11, pp. 4439-4449, 1998.

[16] R. E. Stratmann, G. E. Scuseria, and M. J. Frisch, "An efficient implementation of time-dependent density-functional theory for the calculation of excitation energies of large molecules," The Journal of Chemical Physics, vol. 109, no. 19, pp. 8218-8224, 1998.

[17] T. Yanai, D. P. Tew, and N. C. Handy, "A new hybrid exchangecorrelation functional using the Coulomb-attenuating method (CAM-B3LYP)," Chemical Physics Letters, vol. 393, no. 1-3, pp. 51-57, 2004.

[18] J. Preat, "Photoinduced energy-transfer and electron-transfer processes in dye-sensitized solar cells: TDDFT insights for triphenylamine dyes," The Journal of Physical Chemistry C, vol. 114, no. 39, pp. 16716-16725, 2010.

[19] B. Camino, M. de La Pierre, and A. M. Ferrari, "Photoelectrochemical properties of the CT1 dye: a DFT study," Journal of Molecular Structure, vol. 1046, pp. 116-123, 2013.

[20] A. Irfan, R. Jin, A. G. Al-Sehemi, and A. M. Asiri, "Quantum chemical study of the donor-bridge-acceptor triphenylamine based sensitizers," Spectrochimica Acta Part A: Molecular and Biomolecular Spectroscopy, vol. 110, pp. 60-66, 2013.

[21] S. Jungsuttiwong, R. Tarsang, T. Sudyoadsuk, V. Promarak, P. Khongpracha, and S. Namuangruk, "Theoretical study on novel double donor-based dyes used in high efficient dye-sensitized solar cells: the application of TDDFT study to the electron injection process," Organic Electronics: Physics, Materials, Applications, vol. 14, no. 3, pp. 711-722, 2013.

[22] E. J. Meijer, D. M. de Leeuw, S. Setayesh et al., "Solutionprocessed ambipolar organic field-effect transistors and inverters," Nature Materials, vol. 2, no. 10, pp. 678-682, 2003.

[23] V. Hernández, J. T. L. Navarrete, and J. L. Marcos, "Electronic structure and lattice dynamics of polyfuran," Synthetic Metals, vol. 41, no. 3, pp. 789-792, 1991.

[24] F. B. Kooistra, J. Knol, F. Kastenberg et al., "Increasing the open circuit voltage of bulk-heterojunction solar cells by raising the LUMO level of the acceptor," Organic Letters, vol. 9, no. 4, pp. 551-554, 2007.

[25] J. J. M. Halls, J. Cornil, D. A. dos Santos et al., "Charge- and energy-transfer processes at polymer/polymer interfaces: a joint experimental and theoretical study," Physical Review B, vol. 60, no. 8, pp. 5721-5727, 1999.

[26] M. Fall, J.-J. Aaron, and D. Gningue-Sall, "Luminescence properties of poly(3-methoxythiophene)-bithiophene composite oligomers," Journal of Fluorescence, vol. 10, no. 2, pp. 107-111, 2000.

[27] M. Cossi, N. Rega, G. Scalmani, and V. Barone, "Energies, structures, and electronic properties of molecules in solution with the C-PCM solvation model," Journal of Computational Chemistry, vol. 24, no. 6, pp. 669-681, 2003.

[28] V. Barone and M. Cossi, "Quantum calculation of molecular energies and energy gradients in solution by a conductor solvent model," The Journal of Physical Chemistry A, vol. 102, no. 11, pp. 1995-2001, 1998.

[29] J. F. Pan, S. J. Chua, and W. Huang, "Quantum calculation of molecular energies and energy gradients in solution by a conductor solvent model," Chemical Physics Letters, vol. 363, no. 1-2, pp. 18-24, 2002.

[30] U. Salzner, J. B. Lagowski, P. G. Pickup, and R. A. Poirier, “Comparison of geometries and electronic structures of polyacetylene, polyborole, polycyclopentadiene, polypyrrole, polyfuran, polysilole, polyphosphole, polythiophene, polyselenophene and polytellurophene," Synthetic Metals, vol. 96, no. 3, pp. 177-189, 1998.

[31] A. Kraak and H. Wynberg, "Charge-transfer interaction of dithienyls and cyclopentadithiophenes with 1,3,5-trinitrobenzene (TNB)," Tetrahedron, vol. 24, no. 10, pp. 3881-3885, 1968.

[32] M. Dietrich and J. Heinze, "Poly $\left(4,4^{\prime}\right.$-dimethoxybithiophene)-a new conducting polymer with extraordinary redox and optical properties," Synthetic Metals, vol. 41, no. 1-2, pp. 503-506, 1991.

[33] H. Zgou, M. Hamidi, M. Bouachrine, and K. Hasnaoui, “The DFT study and opto-electronic properties of copolymers based on thiophene and phenylene," Physical and Chemical News, vol. 32, pp. 81-87, 2006.

[34] L. Yang, J.-K. Feng, and A.-M. Ren, "Theoretical studies on the electronic and optical properties of two thiophene-fluorene based $\pi$-conjugated copolymers," Polymer, vol. 46, no. 24, pp. 10970-10981, 2005.

[35] J. L. Bredas, R. Silbey, D. S. Boudreaux, and R. R. Chance, "Chain-length dependence of electronic and electrochemical properties of conjugated systems: polyacetylene, polyphenylene, polythiophene, and polypyrrole," Journal of the American Chemical Society, vol. 105, no. 22, pp. 6555-6559, 1983.

[36] D. Fichou, G. Horowitz, B. Xu, and F. Garnier, "Stoichiometric control of the successive generation of the radical cation and dication of extended $\alpha$-conjugated oligothiophenes: a quantitative model for doped polythiophene," Synthetic Metals, vol. 39, no. 2, pp. 243-259, 1990.

[37] D. Fichou, G. Horowitz, Y. Nishikitani, and F. Garnier, "Semiconducting conjugated oligomers for molecular electronics," Synthetic Metals, vol. 28, no. 1-2, pp. 723-727, 1989.

[38] V. May and O. Kühn, Charge and Energy Transfer Dynamics in Molecular Systems, Wiley-VCH, Berlin, Germany, 2000.

[39] G. Dennler, M. C. Scharber, and C. J. Brabec, "Polymer-fullerene bulk-heterojunction solar cells," Advanced Materials, vol. 21, no. 13, pp. 1323-1338, 2009.

[40] J. W. Chen and Y. Cao, "Development of novel conjugated donor polymers for high-efficiency bulk-heterojunction photovoltaic devices," Accounts of Chemical Research, vol. 42, no. 11, pp. 17091718, 2009. 
[41] Z. Cai-Rong, L. Zi-Jiang, C. Yu-Hong, C. Hong-Shan, W. YouZhi, and Y. Li-Hua, "DFT and TDDFT study on organic dye sensitizers D5, DST and DSS for solar cells," Journal of Molecular Structure: THEOCHEM, vol. 899, no. 1-3, pp. 86-93, 2009.

[42] Y. He, H.-Y. Chen, J. Hou, and Y. Li, "Indene- $\mathrm{C}_{60}$ bisadduct: a new acceptor for high-performance polymer solar cells," Journal of the American Chemical Society, vol. 132, no. 4, pp. 1377-1382, 2010.

[43] S. Günes, H. Neugebauer, and N. S. Sariciftci, "Conjugated polymer-based organic solar cells," Chemical Reviews, vol. 107, no. 4, pp. 1324-1338, 2007.

[44] C. J. Brabec, A. Cravino, D. Meissner et al., "Origin of the open circuit voltage of plastic solar cells," Advanced Funtional Materials, vol. 11, no. 5, pp. 374-380, 2001.

[45] M. C. Scharber, D. Mühlbacher, M. Koppe et al., "Design rules for donors in bulk-heterojunction solar cells-towards $10 \%$ energy-conversion efficiency," Advanced Materials, vol. 18, no. 6, pp. 789-794, 2006.

[46] A. Gadisa, M. Svensson, M. R. Andersson, and O. Inganas, "Correlation between oxidation potential and open-circuit voltage of composite solar cells based on blends of polythiophenes/fullerene derivative," Applied Physics Letters, vol. 84, no. 9, pp. 1609-1611, 2004.

[47] K. Kaneto, K. Yoshino, and Y. Inuishi, "Electrical and optical properties of polythiophene prepared by electrochemical polymerization," Solid State Communications, vol. 46, no. 5, pp. 389391, 1983.

[48] D. Jacquemin, J. Preat, V. Wathelet, M. Fontaine, and E. A. Perpète, "Thioindigo dyes: highly accurate visible spectra with TD-DFT," Journal of the American Chemical Society, vol. 128, no. 6, pp. 2072-2083, 2006.

[49] N. Santhanamoorthi, K. Senthilkumar, and P. Kolandaivel, "Tautomerization and solvent effects on the absorption and emission properties of the Schiff base $N, N^{\prime}$-bis(salicylidene)p-phenylenediamine-a TDDFT study," Molecular Physics, vol. 108, no. 14, pp. 1817-1827, 2010.

[50] J. Vasudevan, R. T. Stibrany, J. Bumby et al., "An edge-over-edge $\mathrm{Zn}(\mathrm{II})$ bacteriochlorin dimer having an unshifted $\mathrm{Q}_{y}$ band. The importance of $\pi$-overlap," Journal of the American Chemical Society, vol. 118, no. 46, pp. 11676-11677, 1996.

[51] H. Scheer and H. H. Inhoffen, "Hydroporphyrins: reactivity, spectroscopy and hydroporphyrin analogues," in The Porphyrins, D. Dolphin, Ed., vol. 2, pp. 45-90, Academic Press, New York, NY, USA, 1978.

[52] R. H. Friend, R. W. Gymer, A. B. Holmes et al., "Electroluminescence in conjugated polymers," Nature, vol. 397, no. 6715, pp. 121-128, 1999. 

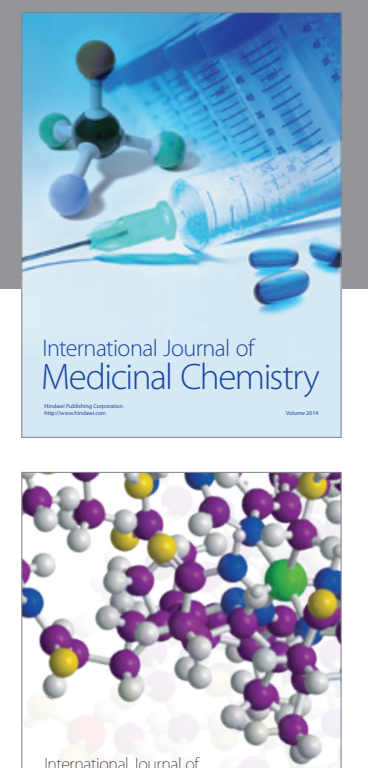

\section{Carbohydrate} Chemistry

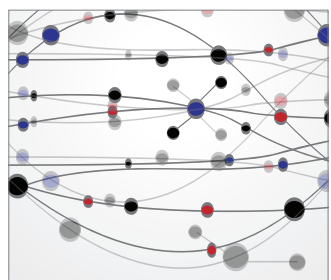

The Scientific World Journal
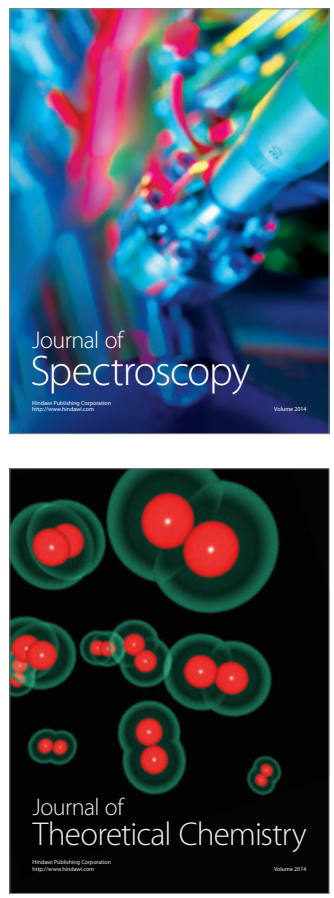
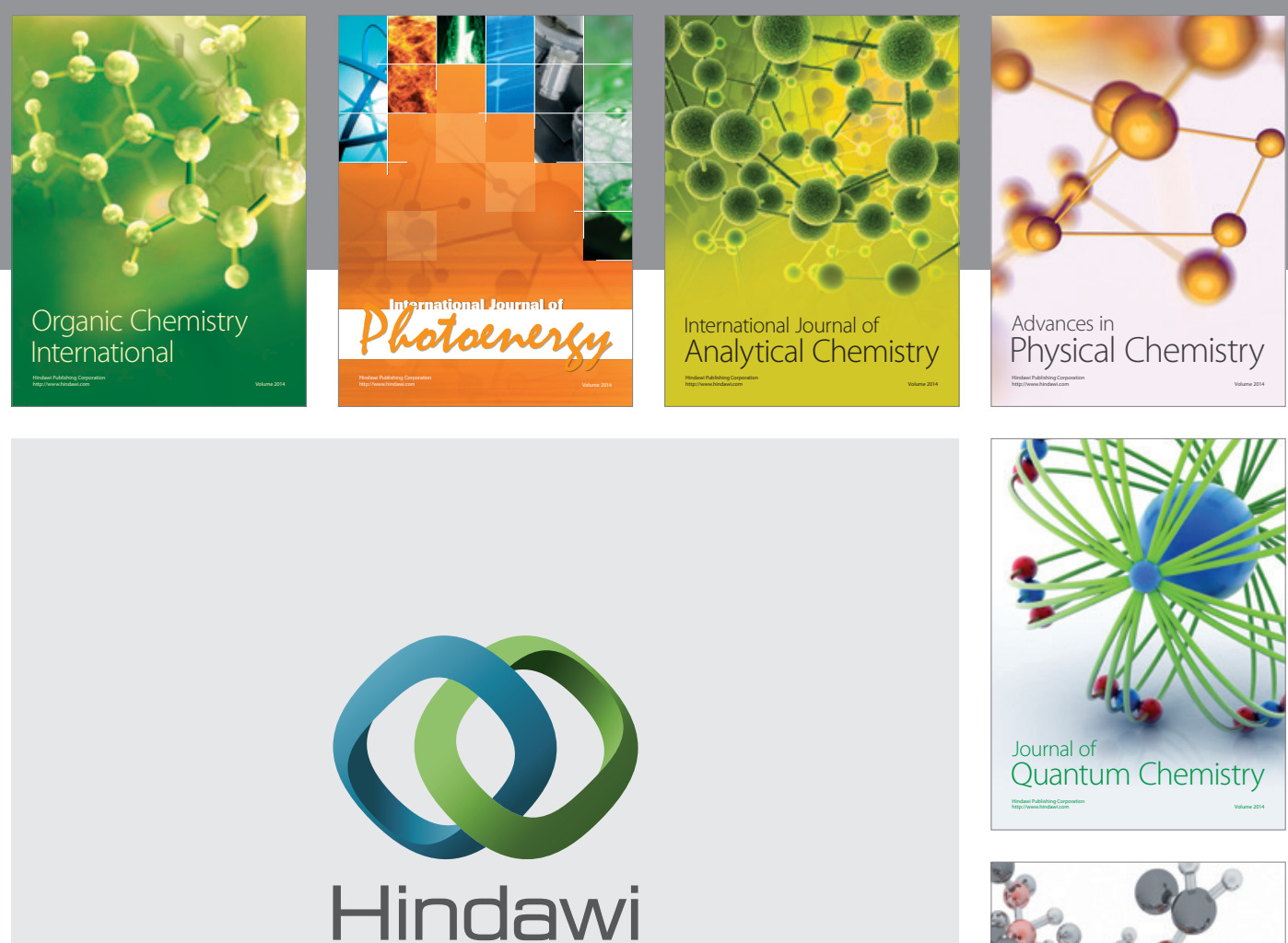

Submit your manuscripts at

http://www.hindawi.com

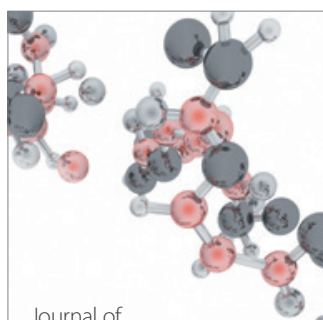

Analytical Methods

in Chemistry

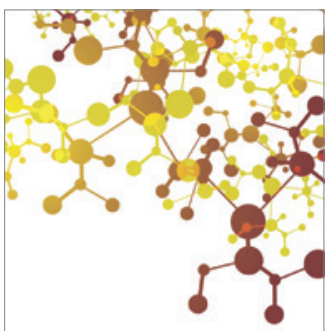

Journal of

Applied Chemistry

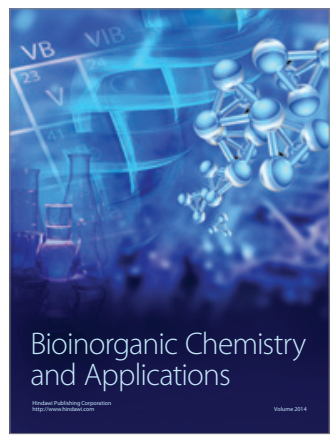

Inorganic Chemistry
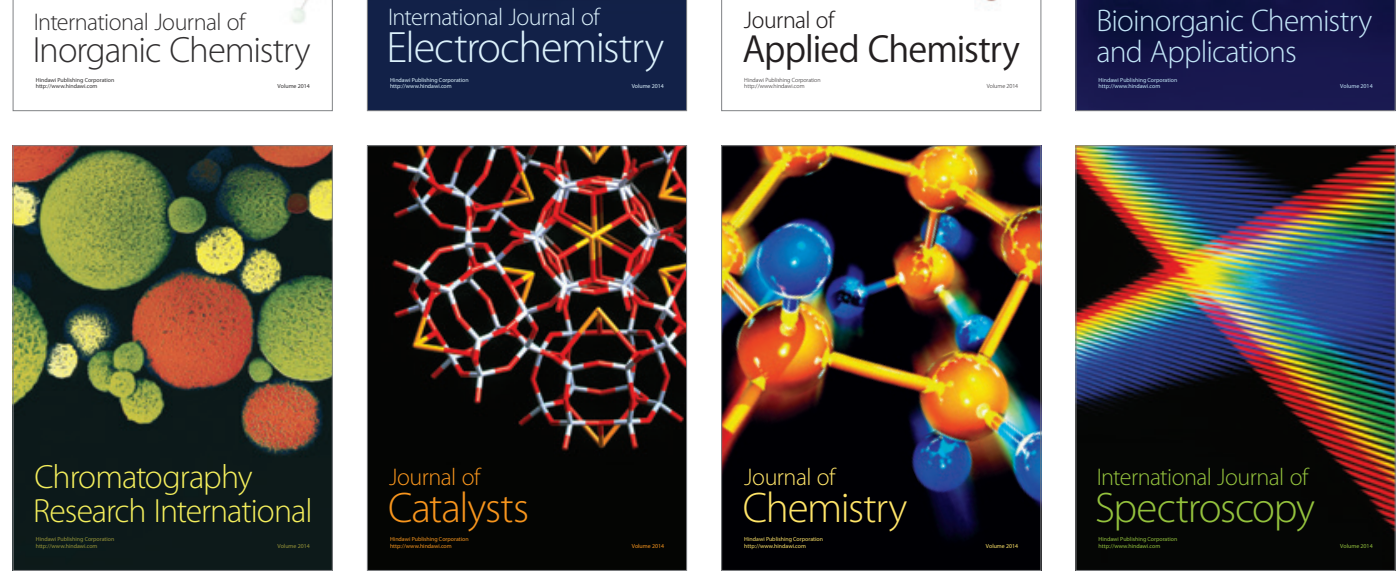